\title{
Operational features of decorative concrete
}

\author{
Olga Bazhenova $^{1 *}$ and Maxim Kotelnikov ${ }^{1}$ \\ ${ }^{1}$ Moscow State University of Civil Engineering, Yaroslavskoe shosse, 26, Moscow, \\ 129337, Russia
}

\begin{abstract}
This article deals with the questions of creation and use of decorative and finishing concrete and mortar. It has been revealed that the most effective artificial rock-imitating stone materials are those made of decorative concrete with the opened internal structure of material. At the same time it is important that the particles of decorative aggregate should be distributed evenly in the concrete volume. It can be reached only at a continuous grain-size analysis of the aggregate from the given rock. The article tackles the necessity of natural stone materials imitation for the cement stone color to correspond to the color of the rock. The possibility of creation of the decorative concrete imitating rocks in the high-speed turbulent mixer is considered. Dependences of durability and frost resistance of the studied concrete on the pore size and character and also parameters characterizing crack resistance of concrete are received.
\end{abstract}

\section{Introduction}

In Russia and in a number of foreign countries, there are wide-ranging studies on getting new durable decorative and finishing materials that can improve a decorative and artistic look and raise operational properties of buildings and constructions.

Items of exterior finishing are placed in more difficult working conditions in comparison with other elements of designs. They are put under influence of climatic factors and mechanical tension at the same time. On the surfaces of finishing materials various defects in the process of operation are observed, which are caused by influence of fluctuations of temperature, humidity of air, impact of wind, rainfall and solar radiation, household and industrial impurity in the atmosphere (dust, soot, carbon black), impacts of static loading, thermoelastic and shrinkable tension [3,4]

It is necessary to include sanitary and hygienic, operational and technical, esthetic requirements, durability, industrial and technological effectiveness in production and economic efficiency that can be referred to general requirements to finishing materials and items [5]. Decorative and finishing concretes and mortars have also been developed and applied a lot. At present, they are considered as structural and finishing materials used in the factory for manufacturing of concrete and reinforced concrete items with a finished front area. Thanks to the use of white and colored rocks, the palette of finishing concretes and mortars has significantly expanded. On the basis of various mineral binding and decorative

\footnotetext{
* Corresponding author: sofia.bazhenova@gmail.com
} 
cements in combination with colored aggregates, semi-finished items are manufactured, in particular, dry mixes for decorative finishing of blocks, panels and other structural elements of buildings, and finished products with finished front area [2-6].

Properties of decorative cements in many respects depend on quality of cement clinker, and properties of the coloring tincture [7,8]. Therefore tinctures have to be resistant to effect of alkalis, sunlight and atmospheric influences, high coloring ability and also make weak impacts on physical and mechanical properties of cements. Contents of mineral, synthetic or natural tinctures in the colored Portland cement shouldn't exceed $15 \%$, and organic - no more than $0.5 \%$.

Very strict requirements are imposed to quality of the last in these conditions. They have to suit:

- sufficient coloring ability that allows to add them in mineral quantities, providing thereby preservation of durability of concrete, not creating a considerable extra charge to its cost;

- high resistance to effect of alkalis, solar radiation and atmospheric influences;

- lack of the harmful admixtures which can negatively influence on physical and mechanical properties of the cement paste and the hardened stone or forming salt efflorescence on its surface;

-wide color tincture and reasonable price [7].

Mineral synthetic tinctures are most available and perspective for application in the cement industry, for example, ferrioxide. They can be yellow, cherry-red, brown-red and black. Ochre, saturnine red, manganese ores are most applied among natural tinctures [8].

Magmatic rocks (granite, syenite, diorite, gabbro and many others), sedimentary rocks (limestones, soapstone, sandstone and others) and metamorphic rocks (marble, gneisses) are used as aggregates for decorative concrete. It is very important to study the structure and texture of initial rocks while selecting aggregates.

Rocks are a set of minerals. Minerals are homogeneous in natural rocks in their chemical composition and physical properties. Color of minerals is of very great importance for receiving analogs of the artificial stone materials similar to natural properties according to their exterior signs. The decorative concrete received on usual technology on color cements or with tinctures and on aggregates from rocks (with the opened area) are the best decorative materials imitating natural stones. Opening of the surface of decorative concrete can be carried out by machining with a tool of refractory steels, by sand cleaning under pressure or by cutting blocks into tiles of various sizes [9].

When processing decorative concrete with tools and opening the surface layer, with the correct selection of the aggregate's grain composition, a surface is obtained that is not inferior in its properties to natural stone materials [10].

Decorative concretes and mortars, along with undoubtedly positive properties, have the same drawbacks as conventional concrete and mortar. Concrete is a capillary-porous body, the properties of which are more dependent on porosity. In the formation and subsequent hardening of concrete pores are formed as a result of chemical and physical and mechanical processes. The pore volume in dense concrete is from 9 to $20 \%$, with increasing tincture content in decorative concrete and mortar, its porosity increases. When tinctures with a high specific surface are introduced, they are adsorbed on the grains of cement and aggregate reducing the hydration of cement grains and their adhesion to the aggregate. With an increase in the tincture content, the workability of the mixture decreases, and therefore, when the mechanical action is difficult, the trapped air is difficult to remove [11].

There are various ways to improve the performance characteristics of decorative concrete and mortars. Active mineral additives are applied, which bind calcium hydroxides to poorly soluble calcium hydrosilicates. This helps to increase the strength of cement stone due to the formation of a crystalline splice. However, the use of active mineral additives does not ensure 
complete binding of the excreted calcium oxide. Improvement of the properties of decorative concrete and mortars is possible with the use of surface active substances: the density of cement stone is increased, a fine-grained structure with a system of closed uniformly located pores is formed. Various plasticizing and hydrophobizing additives are used to increase the density of concrete and mortar and to reduce efflorescences on the surface of products and increase of their durability [12-13].

When determining the amount of cement, it is necessary to take into account the fact that for the color of the concrete surface, the color of the cement is of decisive importance, and not only its excess quantity per unit volume of concrete in relation to the established rate. The particular dose of cement depends on the properties of the aggregate and the technology of processing concrete. It can vary from 300 to $500 \mathrm{~kg}$ per $1 \mathrm{~m} 3$ of ready-mixed concrete. When choosing aggregates for decorative concrete, decisive importance has not only their color, but also other properties such as durability, polishability, the presence of primary and secondary impurities, color stability. In the production of aggregates for decorative concrete, the following requirements must be met:

- permanent grain-size composition of the aggregate, its careful classification, increased content of fine fractions and stone powder;

- favorable color range of the aggregate;

- the purity of the aggregate.

The content and grain-size composition of the aggregate per unit volume of concrete should be constant, as the vibrations may affect the properties of concrete, which adversely affects the color tone of the decorative concrete $[8,9]$.

In the process of operation, decorative materials, elements of artistic, decorative, sculptural and monumental works are subjected to aggressive influences, which are divided into two main groups:

- external, causing the destruction of the material or surface of the product;

- internal chemical and structural changes in the material that occur during the hydration of cement.

Defects of the structure of concrete are stress concentrators, as well as channels through which aggressive agents penetrate deep into the concrete. Therefore, in order to increase the durability of decorative concrete and reinforced concrete products and structures, it is necessary to increase the density and strength of surface layers of concrete, often of high porosity, due to sedimentation and water separation when compacting the concrete mix.

An effective way to increase the strength and durability of concrete is the use of silicacontaining additives that interact with calcium hydroxide, increasing the density of the cement stone and improving the contact area between the cement stone and the aggregate [14-15]. The adhesion of cement stone with aggregate is provided by the quality of aggregate surface. The best results can be achieved with partial grinding of the aggregate with the improvement of the shape of the grains (approximating to the cubic shape), activation of their surface (cleaning of aggregates from clay and oxide layers). This will increase the density of concrete, deepen the process of hydration of cement and, as a consequence, reduce its specific consumption and improve the quality of decorative concrete [16-20].

Thus, the conducted analysis of production and application of decorative concrete in construction showed that the most effective artificial stone materials imitating rocks are decorative concretes with the opened inner structure of the material. In this case, it is important to distribute aggregate grains uniformly in the volume of concrete. This can be achieved only with a certain continuous granulometry of the aggregate from a given rock. In this case, the use of quartz sand as a fine aggregate is excluded, since during machining there will be either sanding out of the sand or changing the tone of the original rock. Therefore, to obtain a uniform texture of decorative concrete, it is necessary to use an aggregate of all fractions from the original rock only. To imitate natural stone materials, it is necessary that 
the cement stone has a color corresponding to the tone of the rock. This is achieved by using mineral or organic tinctures that are stable in alkaline environments.

\section{Method}

Rubble of red granite with a bulk density of $1290 \mathrm{~kg} / \mathrm{m}^{3}$, a density of $2.5 \mathrm{~g} / \mathrm{cm}^{3}$, a water requirement of $6.1 \%$ was used in the experiment as an aggregate for decorative concretes. To reduce water consumption and improve the quality of concrete, superplasticizer C-3 (in powder form), microsilica - ferroalloy production waste with a specific surface area of 2000 $\mathrm{m}^{2} / \mathrm{kg}$, density $2.2 \mathrm{~g} / \mathrm{m}^{3}$, bulk density $0.2-0.25 \mathrm{~g} / \mathrm{cm}^{3}$ were used. Iron saturnine red with a specific surface of about $980 \mathrm{~m}^{2} / \mathrm{kg}$ was used as the tinctures.

The preparation of decorative concrete mixtures was carried out in a high-speed turbulent mixer with rotor rotation at a speed of $600 \mathrm{rpm}$ equipped with a propeller-like nozzle made of high-strength steel. When the components of the concrete mix are mixed, the coarse aggregate is crushed to form a continuous granulometry of the grains, the activation of the cement and an increase in the uniformity of the concrete mixture.

Systematized studies of the structure of strength, deformation properties, fracture toughness and frost resistance of decorative concretes were carried out for various cement and microsilica costs and the same mobility of the concrete mixture.

Samples of cubes were made $10 \times 10 \times 10 \mathrm{~cm}$. The samples were tested after heat and moisture treatment in 7 days. The total and group porosity was determined in three degrees of saturation (successively over water, in water and under vacuum to constant mass), compressive strength, parametric points of the microcrack formation process under static loading, frost resistance and stress intensity factor.

\section{Results and Discussion}

The compositions of the concretes obtained are listed in Table 1. In all compositions, the consumption of superplasticizer C-3 in concrete was $0.63 \%$, and aggregate (iron saturnine red) $-5 \%$ of cement mass.

Table 1. Compositions of decorative concretes

\begin{tabular}{|c|c|c|c|c|c|c|}
\hline \multirow{2}{*}{$\begin{array}{c}\text { No of } \\
\text { composition }\end{array}$} & \multicolumn{4}{|c|}{ Consumption of materials, $\mathrm{kg} \mathrm{m}^{3}$} & \multirow{2}{*}{ W/C } & $\begin{array}{c}\text { Precipitation } \\
\text { of the cone, } \\
\text { cm }\end{array}$ \\
\hline & Cement & Water & Aggregate & Microsilica & & $6-8$ \\
\hline 1 & 500 & 167 & 1767 & 40 & 0.33 & $6-8$ \\
\hline 2 & 580 & 170 & 1683 & 46.4 & 0.29 & $6-8$ \\
\hline 3 & 660 & 173 & 1597 & 52.8 & 0.26 & $12-16$ \\
\hline 4 & 575 & 174 & 1674 & 46 & 0.3 & $12-16$ \\
\hline 5 & 650 & 177 & 1597 & 52 & 0.27 & $12-16$ \\
\hline 6 & 740 & 186 & 1542 & 59.2 & 0.25 & \\
\hline
\end{tabular}

As a result of mathematical processing of the experimental data, the strengths and frostresistance of the examined concrete have been found to depend on the size and nature of the pores, as well as the parameters characterizing the crack resistance of concrete. A characteristic feature of the studied concrete prepared according to the developed method is that they have a different contact area between the cement stone and the aggregate compared to conventional concrete, because as a result of the preliminary treatment of the aggregate in the modified turbulent mixer, the adhesion of the cement stone to the aggregate is substantially improved and the composition of the new phases and the nature of the pores change. This is evidenced by data on the definition of group porosity in three degrees of 
saturation. The properties most influenced by the pores of the second group which characterize, mainly, the volume of capillary pores. The properties of decorative concretes are presented in Table 2 .

Table 2. Properties of decorative concrete

\begin{tabular}{|c|c|c|c|c|c|}
\hline No & $\begin{array}{c}\text { Total } \\
\text { porosity, } \\
\% \mathrm{P}_{\mathrm{o}}\end{array}$ & $\begin{array}{c}\text { Porosity of } \\
\text { group 2, } \\
\% \mathrm{P}_{2}\end{array}$ & $\begin{array}{c}\text { Strength, } \\
\mathrm{MPa}\end{array}$ & $\begin{array}{c}\text { Frost- } \\
\text { resistance, } \\
\text { cycle }\end{array}$ & $\begin{array}{c}\text { Stress intensity } \\
\text { factor } \\
\mathrm{MN} / \mathrm{m}^{3 / 2}\end{array}$ \\
\hline 1 & 11.1 & 3.4 & 54.5 & 300 & 3.12 \\
\hline 2 & 10.5 & 2.6 & 63.7 & 350 & 3.2 \\
\hline 3 & 10.0 & 1.6 & 72.4 & 400 & 3.26 \\
\hline 4 & 12.0 & 3.5 & 53.4 & 250 & 3.0 \\
\hline 5 & 12.2 & 2.7 & 62.9 & 300 & 2.98 \\
\hline 6 & 12.4 & 2.0 & 73.2 & 250 & 2.95 \\
\hline
\end{tabular}

The introduction of microsilica and superplasticizing additive C-3 contribute to a decrease in the content of macropores and increase strength, while maintaining high mobility of the concrete mix. The volume of macropores in concrete depends on the degree of hydration of cement in concrete, that is, on the conditions of hardening. The degree of hydration was determined by X-ray diffraction. For the studied concrete it was $0.4-0.5$. By the value of macroporosity (capillary), the concrete under study should be classified as particularly dense.

The relationship between the cubic strength of concrete and the porosity of the second group $\left(\mathrm{P}_{2}\right)$ is established, which is described by the following equation:

$$
R=78.9+0.19 P_{2}-2.17 P_{2}^{2}
$$

The concrete cracking is characterized by a stress intensity factor $(\mathrm{Kc})$, which in turn is associated with the main defect of concrete - pores, the presence of which causes the greatest concentration of stresses. Therefore, the dependence of Kc on the total porosity of concrete was established, having the form:

$$
K c=4.96-0.21 P_{0}+0.004 P_{0}^{2}
$$

In frozen concrete, ice is formed first in large, and then in shallow pores, due to the different capacity of water enclosed in these pores, to pass into ice. When preparing decorative concrete mixtures in a modified turbulent mixer, the capillary porosity of concrete decreases, which leads to an increase in the frost resistance of concrete. Dependence of frost resistance on the porosity of the second group is described by the following equation:

$$
F=359+66.5 P_{2}-27 P_{2}{ }^{2}
$$

The established dependencies make it possible to predict the strength and deformation properties of decorative concrete, as well as the fracture toughness and frost resistance in the process of their operation.

\section{Conclusion}

Analyzing the test results, and summarizing the above mentioned, we can draw the following conclusions:

- the preparation of decorative concrete mixes in a modified turbulent mixer allows to partially crush the aggregate, change its grain shape, approaching the cubic one, break down weak grains, reduce the number of microdefects, activate the aggregate surface and improve the contact area between the cement stone and aggregate; 
- the influence of cement consumption and microsilica under different workability on the structure, strength and other characteristics of decorative concrete has been established;

- dependences of strength and frost resistance of concrete from the second group of porosity (capillary) are determined, and a relationship between the total porosity and the stress intensity factor is established;

- dependences of frost resistance, stress intensity factor, parameters of the microcrack formation process prepared in a modified turbulent mixer on the composition and structure characteristics are obtained.

Obtained decorative concrete, imitating various rocks, can be used for the manufacturing of pedimental slabs, paving stones, curbstone, floor slabs and decoration of interiors, as well as artistic and decorative products.

\section{References}

1. Yu. Bazhenov, V. Falikman, Build-Info, 1-2, 289-290 (2007).

2. V. Egorov, Buil. S. of Moscow, 2, 14-18 (2007).

3. S. Nikolaev Sec.tech. and eng. Sys., 1, 16-20 (2006).

4. Yu. Bazhenov, E. Korolev, N. Lukutsova, S. Zavalishin, Bull. of MGSU, 6, 73-78 (2012).

5. K. Sullivan, Cem. and its appl., 4, 82-86 (2015).

6. O. Bazhenova, Build. Mat., equip., tech. of the XXI cen., 3, 15 (2003).

7. B.Ya. Trofimov, L.Ya. Kramar, Vestnik of the South Ural State Univ., 15 (191), 36-38 (2010)

8. L. Marco Raw materials for decorative concrete. (Moscow: Stroyizdat, 1983).

9. V. Tserkovnikov. Manual on the technology of obtaining artificial stone materials for works of monumental and decorative art. (Tula: PKS, 1987).

10. O.Yu. Bazhenova, S.I. Bazhenova Adv. in mod. Sci., 6, vol.3, 21-23 (2016).

11. P.P Gajurov, A.P. Zubehin, Cement, 7, 28-30 (1995).

12. G.I. Berdov, N.I. Nikonenko, L.V. Ilyina, Izvestiya VUZ. Build., 12, 25-30 (2011).

13. O.Yu. Bazhenova, V.E. Kaushansky, Construction and decoration materials. Standards of XXI century XIII International Workshop of ATAM. (Novosibirsk, 2006).

14. V.I. Kalashnikov, O.V. Suzdaltsev, R.A. Dryanin, G.P. Sekhposian, Izvestiya VUZ, 7 (667), 11-21 (2014).

15. L.A. Urkhanova, V.E. Rosina, Bull. of the Irkutsk State Tech. Univ., 10 (57), 97-100. (2011)

16. V.V. Loshak, S.V. Cherkasov, V.V. Vlasov // Sci. Bull. Of Voronezh State Arch. and Constr. Univ., 3-4, 61-66 (2011).

17. D.K. Timokhin, Yu.S. Geranina, Res.-en.-eff. Tech. in the constr. complex of the region. 2(6), 173-176. (2015).

18. E.A. Shchetkova, G.G. Kashevarova // Bull. of the Perm Nat. Res. Polytechnic Univ. 3(27), 143-151 (2017).

19. S. Guziy, S. Terenchuk, ScienceRise, 2 (26), Vol. 9, 49-54 (2016).

20. V.I. Kalashnikov, O.V. Suzdaltsev, M.N. Moroz, V.V. Pausk, Build. Mat. 3, 16-19 (2015) 